\title{
Working
}

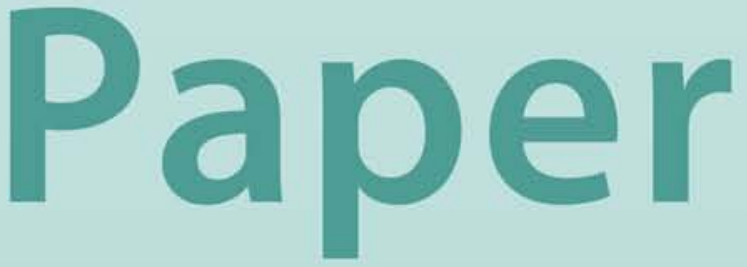




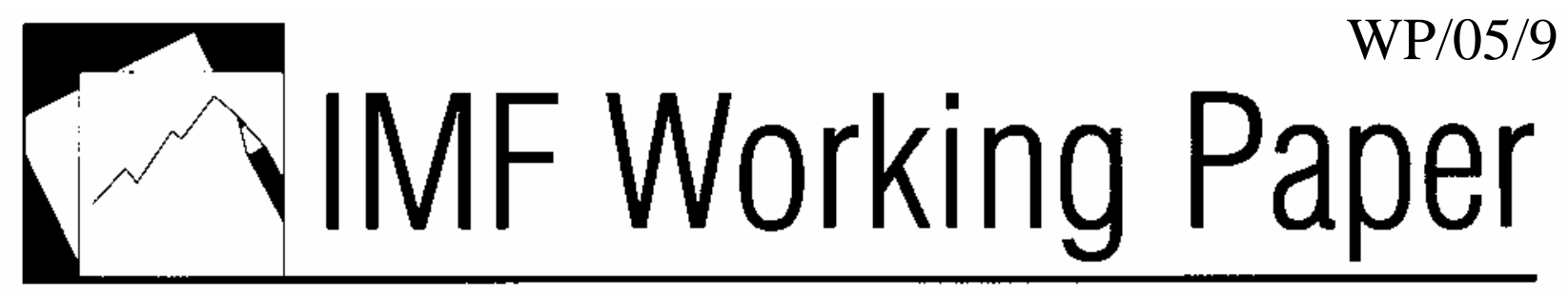

\section{Asset Mispricing Due to Cognitive Dissonance}

Burkhard Drees and Bernhard Eckwert 


\title{
IMF Working Paper
}

IMF Institute

\author{
Asset Mispricing Due to Cognitive Dissonance \\ Prepared by Burkhard Drees and Bernhard Eckwert ${ }^{1}$ \\ Authorized for distribution by Sunil Sharma
}

January 2005

\begin{abstract}

\section{This Working Paper should not be reported as representing the views of the IMF.} The views expressed in this Working Paper are those of the author(s) and do not necessarily represent those of the IMF or IMF policy. Working Papers describe research in progress by the author(s) and are published to elicit comments and to further debate.

The behavior of equity prices is analyzed in a general equilibrium model where agents have preferences not only over consumption but also (implicitly) over their beliefs. To alleviate cognitive dissonance, investors endogenously choose to ignore information that conflicts too much with their ex ante expectations. Depending on the new information that is released, systematic overvaluation and undervaluation of equity prices arise, as well as too much and too little equity price volatility. The distortion in the asset pricing process is closely related to the precision of the information.
\end{abstract}

JEL Classification Numbers: G11, G12

Keywords: Asset pricing, behavioral finance, cognitive dissonance

Author(s) E-Mail Address: bdrees@imf.org; beckwert@wiwi.uni-bielefeld.de

\footnotetext{
${ }^{1}$ Burkhard Drees is in the Asian Division of the IMF Institute. Bernhard Eckwert is Professor of Economics at the University of Bielefeld (Germany). We thank Peter Breuer, Woon Gyu Choi, R. Sean Craig, Miguel Messmacher, Sunil Sharma, Felix Vardy, and seminar participants at the IMF Institute for their comments.
} 


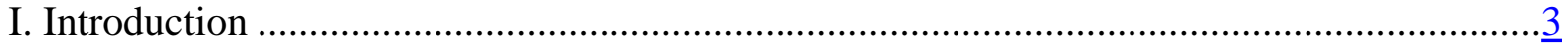

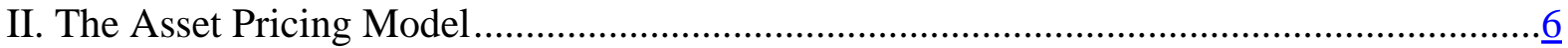

A. Benchmark Case 1: All Investors Heed the Information Signal ..............................

B. Benchmark Case 2: All Investors Ignore the Information Signal ...........................

III. Asset Pricing with Cognitive Dissonance...............................................................10

IV. How Information Affects Asset Prices ................................................................ $\frac{13}{14}$

A. Full-Information Equilibria: All Investors Heed the Information .........................14

B. Slightly Less Favorable Information is Ignored by Some Investors ......................16

C. Sufficiently Bad News is Ignored by All Investors..........................................

D. Highly Unfavorable and Highly Favorable News is Heeded by Some Investors and Ignored by Others....................................................................................

E. At Most Half of the Investors Heed Highly Favorable and Highly Unfavorable

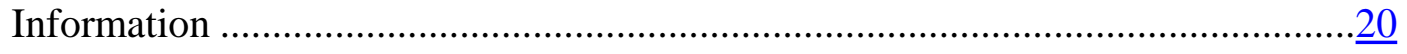

V. The Less Informative the Signal, the Larger the Mispricing …....................................21

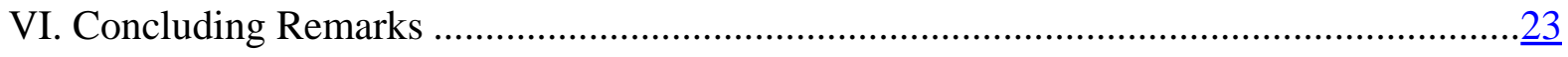

Figures

1. Value Functions of the Investors' Optimization Problem .............................................25

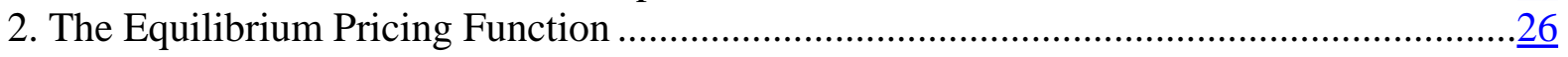

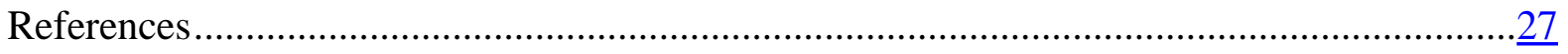




\section{INTRODUCTION}

Growing evidence casts doubt on the view that asset prices are determined by investors' unbiased expectations of fundamental values, ruling out persistent over- and undervaluation of assets. ${ }^{2}$ To explain the occurrence of mispricing, behavioral finance has analyzed various systematic psychological phenomena that might interfere with efficient asset pricing. However, one of the most influential theories in social psychology-namely, cognitive dissonance-has not been applied to asset pricing. This paper attempts to fill that gap by allowing for the possibility that investors might alter their beliefs in response to conflicting cognitions: when information about the assets they hold is sufficiently unfavorable, investors might discard the information because it conflicts with their selfimage of being smart investors. We show how this type of behavior can be modeled as the outcome of an individual optimization problem, how it can lead to over- and undervaluation of assets, and how it can cause sometimes too much and sometimes too little asset price volatility.

A broad range of evidence suggests that asset prices may not always be priced efficiently. In addition to the well-known equity premium puzzle (Mehra and Prescott, 1985) and indications of excess volatility (Shiller, 1981), recent studies have found evidence for underreaction and overreaction of stock prices. ${ }^{3}$ At short horizons, stock returns tend to exhibit positive autocorrelation, indicating that stock prices underreact to news as new information is only slowly incorporated into the prices. ${ }^{4}$ By contrast, over horizons of three to five years, the autocorrelation in stock returns seems to be slightly negative, suggesting that stock prices overreact to extreme news, be it good or bad. ${ }^{5}$ Moreover, stock market crashes are typically difficult to reconcile with market efficiency, in part because the new information revealed just prior to stock market crashes does not usually warrant the huge drop in stock prices. All of these deviations from the efficient markets model appear to be systematic and remain largely unresolved within models where rational investors maximize their utility and/or material wealth and regard their information sets as exogenous (De Bondt and Thaler, 1995). ${ }^{6}$

\footnotetext{
2 The concept of efficient capital markets is reviewed in Fama (1991), LeRoy (1989), West (1988), and Hess and Reinganum (1979); see also Malkiel (2003) and Shiller (2003).

${ }^{3}$ For recent attempts to explain the equity premium puzzle, see Bansal and Yaron (2004), and Campbell and Cochrane (1999).

${ }^{4}$ See, for example, Cohen and others (2002), Rouwenhorst (1998), Jegadeesh and Titman (1993), Bernard (1992), and Cutler and others (1991).

${ }^{5}$ See, for example, Chopra and others (1992), Fama and French (1988), Campbell and Shiller (1988), and De Bondt and Thaler (1985).

${ }^{6}$ For a dissenting point of view that interprets the evidence of under- and overreaction as chance deviations consistent with the Efficient Markets Hypothesis, see Fama (1998).
} 
To explain these phenomena, behavioral finance has integrated concepts developed by psychologists into asset pricing models (see Barberis and Thaler, 2002; Daniel and others, 2002; and Hirshleifer, 2001, for reviews). ${ }^{7}$ Psychologists find that agents are not purely rational in processing and interpreting information. Research indicates that people tend to systematically underweight some types of information and overweight other types (for surveys, see Rabin, 1998; and Shiller, 1998). Three closely related biases, in particular, have been identified, and their implications for asset pricing have been analyzed: (1) overconfidence-people tend to overstate their abilities and the precision of their knowledge (Daniel and others, 1998; and Odean, 1998); (2) availability/representativeness heuristicagents tend to overweight memorable and vivid evidence, and they tend to underweight overall prior odds (Tversky and Kahneman, 1974); and (3) confirmatory bias-decision makers tend to overweight information that is consistent with their beliefs, and underweight information that is at odds (Fiske and Taylor, 1991; Rabin and Schrag, 1999).

In this paper, we introduce cognitive dissonance-one of the most influential theories of social psychology_-into an asset pricing model. ${ }^{8}$ Festinger (1957) postulated that if individuals are presented with conflicting cognitions (pieces of knowledge), they suffer distress and feel compelled to change one of these cognitions. They either avoid information that is likely to increase dissonance or select information that is consistent with their a priori beliefs. In particular, individuals tend to have a positive self-image and do not want to feel incompetent. Thus, information that conflicts with the positive self-image tends to be ignored, rejected, or misinterpreted, or the conflict is resolved by changes in other beliefs (Harmon-Jones and others, 1999). For example, persons who have made decisions often tend to discard information that would suggest that the decisions were made in error. In general, the potential for cognitive dissonance can lead to the avoidance of information that could be inconsistent with one's beliefs and attitudes.

Biases in decision making - including the effects of cognitive dissonance-may be particularly prevalent in financial market settings, since investors are confronted with complex and ambiguous evidence, and they have to selectively collect and interpret information. When faced with complex and ambiguous evidence, agents tend to overstate the strength of confirming information and to downplay the reliability of conflicting evidence (Rabin, 1998). Particularly when processing available information is costly so that some selection of information will have to be made, an investor might selectively ignore

\footnotetext{
${ }^{7}$ Some papers have tried to motivate models of seemingly irrational markets by introducing behavioral concepts such as "myopic loss aversion” (Benartzi and Thaler, 1995), "wealthinduced social status" (Zou, 1994; Bakshi and Chen, 1996), and "momentum trading strategies” (Grinblatt and others, 1995). See also the literature on "bounded rationality" (Gigerenzer and Selten, 2001).

${ }^{8}$ The concept of cognitive dissonance was originally developed by Festinger (1957). For an application of the concept of cognitive dissonance to an economic problem, see Akerlof and Dickens (1982); they apply it to explain the behavior of workers in hazardous industries.
} 
information about his asset portfolio if heeding that information reduces (expected) welfare. ${ }^{9}$ Moreover, these biases are particularly prevalent when the complexity and ambiguity of the situation requires the use of prior hypotheses to interpret data and to decide which data to scrutinize_-another key feature of the decision making environment in financial markets.

In this paper, we construct a general equilibrium model where the quasirational behavior associated with cognitive dissonance emerges endogenously; that is, individuals choose to ignore unfavorable or contradictory information. ${ }^{10}$ In our model investors make investment decisions in the initial period based on prior beliefs about asset payoffs. If the information that arrives in the next period conflicts too much with their ex ante beliefs that they made the right portfolio choice, they choose to ignore the information. The thresholds that separate information that is heeded from information that is ignored are determined within the model and not exogenously set. Specifically, we model cognitive dissonance behavior by assuming that if the expected utility in the second period conditional on the signal exceeds the unconditional expected utility without the signal, the investor will heed the information; otherwise, he will ignore it.

The way we model cognitive dissonance may appear ad hoc, but we consider it a tractable approach with some advantages. A possible alternative approach (similar to the one adopted by Akerlof and Dickens, 1982) would arbitrarily assume psychological costs associated with deviations from the cognition of a positive self-image. The investor's choice over the information set would then be modeled as a tradeoff between the loss from a suboptimal portfolio choice if the information is discarded and the costs of psychological discomfort due to cognitive dissonance when the information is heeded. We do not follow this route; instead we want to stay as close to the rational model as possible to facilitate direct comparisons of equilibrium outcomes based on rational decision making with those involving quasirational decision making.

Unlike in other models where quasirational behavior is assumed throughout, in our model, what looks like rational behavior emerges endogenously under some circumstances and quasirational behavior under other circumstances. In fact, and this is a relatively novel

${ }^{9}$ Rabin and Schrag (1999) assume that agents not only simply dismiss but sometimes also misinterpret information that is in conflict with their prior beliefs. They show that this confirmatory bias leads to overconfidence.

${ }^{10}$ Other papers have also modeled endogenous beliefs. Brunnermeier and Parker (2004) endogenize beliefs that differ from rational expectations by letting agents choose "optimal" beliefs in a model where welfare depends not only on current flow utility but also on expected future utility flow. In Yariv (2002), agents choose beliefs (and sometimes endogenously misread signals) by maximizing utility that has two components: standard utility ("instrumental utility") and "belief utility" that stems from changes in beliefs. In Carrillo and Mariotti (2000), strategic ignorance serves as a disciplining device in an intrapersonal game of individuals with dynamically inconsistent preferences. 
feature of our approach, even though agents have identical preferences and endowments, they do not necessarily behave in the same way as a result of general equilibrium effects: in certain equilibria some agents choose to act quasirationally, while others act rationally. Since investors choose their information sets by deciding whether to heed or to ignore some information, our model may provide micro foundation for some nonstandard behavioral assumptions.

Our key results describe how the asset price responds to the information that is revealed in the second period. We show how the equity price can both under- and overreact to a publicly observable signal-unlike in Daniel and others (1998) who found overreaction to the private signal and underreaction to the public signal. ${ }^{11}$ Equity prices overreact to moderately negative information, while prices underreact to extremely positive and extremely negative information. For slightly worse information, the price becomes totally insensitive to the news. Since the deviation from rational behavior is endogenous, the mispricing is bounded-if information is sufficiently negative, it is advantageous for some investors to revert to rational behavior because these informed investors can earn abnormal profits based on their superior information that compensate them for the discomfort associated with cognitive dissonance. As a result, equity prices become again sensitive to information that is extremely unfavorable. However this arbitrage mechanism is not perfect, and price distortions remain in equilibrium. Moreover, excessive price volatility and excessive price stability arise endogenously. We also describe how the distortions of the pricing process are related to the precision of the information. In our model, the price mechanism remains distorted even if the signal becomes asymptotically uninformative-a finding that might contribute to an understanding of the emergence of sunspot equilibria.

The paper is organized as follows. The next section describes the model and outlines the two benchmark cases when all investors heed the information and when all investors ignore the information. Section III derives the equilibrium of the model with cognitive dissonance. Section IV explains how different realizations of the information signal affect the equilibrium asset price, and Section $\mathrm{V}$ explores the effects of changing the information content of the signal. Concluding remarks and a discussion of further research are presented in Section VI.

\section{The Asset Pricing Model}

The economy lasts for three periods and is populated by a continuum of identical agents, $I=[0,1]$. Agents consume only at time 3 . Preferences are described by the utility

${ }^{11}$ Barberis and others (1998) explain under- and overreaction of stock prices in a model with Baysian investors who act based on an incorrect model of the asset payoff process. In Hong and Stein (1999), price over- and underreaction arises from the interaction between two types of boundedly rational agents ("news watchers" and "momentum traders"). A model of asset price overreaction that does not resort to behavioral finance assumptions is Aiyagari and Gertler (1999): due to margin constraints, traders are forced to liquidate their positions after a price drop, pushing prices down further than in frictionless markets. 
function $U(c)=-\exp (-\beta c)$, where $\beta$ is the constant degree of absolute risk aversion; $c$ is the final wealth to be consumed by the agent at time 3 . Two assets are available: a risky asset (shares) and a safe asset, with a price that is normalized to one (numeraire). At time 1, each agent is endowed with one unit of the risky asset and $e>0$ units of the safe asset. The safe asset pays a fixed rate of return, $r$, in periods 2 and 3 , and is in perfectly elastic supply. The second asset pays a random dividend, $\tilde{d}=\tilde{\gamma}+\widetilde{\varepsilon}$, in period 3 . The variables $\tilde{\gamma}$ and $\tilde{\varepsilon}$ are stochastically independent random variables with $E\{\tilde{\gamma}\}>0$ and $E\{\tilde{\varepsilon}\}=0$. The realization of $\tilde{\varepsilon}$ can be observed at time 2 , while $\tilde{\gamma}$ will not be revealed prior to time 3 . Thus some information about the risky asset's payoff is revealed before the dividend, $\tilde{d}$, actually materializes. We denote the realizations of the random variables $\tilde{\gamma}$ and $\tilde{\varepsilon}$ by $\gamma$ and $\varepsilon$. In light of the new information that is received at time 2 , investors may reconsider their portfolio decisions made at time 1 .

The sequence of events can be summarized as follows:

- Period 1: investors choose their portfolios and can trade on the asset markets.

- Period 2: the investors observe the signal $\varepsilon$, and then decide whether to heed the information and, if necessary, to reshape their portfolios by trading on the asset markets, or whether to ignore the new information to avoid internal conflict (such as cognitive dissonance).

- $\quad$ Period 3: the investors consume the asset payoffs.

In period 1, each agent can invest his endowment of $e$ units of the safe asset and one unit of the risky asset into a portfolio consisting of both assets. The budget constraint in period 1 is

$$
e+p_{1}=s_{1}+p_{1} \lambda_{1}
$$

where $p_{t}$ is the real price of a share at time $t$, while the price of the safe asset is normalized to $1 ; s_{t}$ denotes the units of the safe asset held at the end of period $t$; and $\lambda_{t}$ denotes the number of shares held at the end of time $t$.

In period 2, the portfolio can be changed subject to the constraint

$$
(1+r) s_{1}+p_{2} \lambda_{1}=s_{2}+p_{2} \lambda_{2}
$$

Wealth (i.e. consumption) in period 3 is

$$
c=(1+r)\left[(1+r) s_{1}+p_{2}\left(\lambda_{1}-\lambda_{2}\right)\right]+(\gamma+\varepsilon) \lambda_{2}
$$

At the beginning of period 2, when the signal $\varepsilon$ is revealed, investors may find themselves facing an internal psychological conflict akin to cognitive dissonance. On the one 
hand, agents want to consider themselves to be smart investors; on the other hand, a realization of the information $\varepsilon$ that differs significantly from the agents' ex ante expectations would indicate that, in hindsight, they might have chosen the wrong portfolio at time 1. To resolve this internal conflict, investors might be prompted to ignore the signal $\varepsilon$. We will model the choice of heeding or ignoring the information as follows: the investor will ignore the new information if his unconditional expected utility (without the information of the signal) is at least as large as the expected utility conditional on the new information. Since the (conditional) expected utility depends, inter alia, on the portfolio choice at time 1, this approach captures the key aspect of cognitive dissonance: information that conflicts too much with the portfolio decision taken earlier will be ignored. To derive the effects of this cognitive bias on asset prices, we will first consider two benchmark cases before we turn to a detailed description of the equilibrium with cognitive dissonance: (1) all investors heed the information, and (2) all investors ignore the information.

\section{A. Benchmark Case 1: All Investors Heed the Information Signal}

To characterize the equilibrium asset prices when investors behave fully rationally and use all available information, the problem is solved backwards in two stages.

$\underline{\text { Stage I: }}$ Suppose an agent has chosen an optimal portfolio $\left(s_{1}^{*}, \lambda_{1}^{*}\right)$ at time 1 . At time 2 , after having observed the signal $\varepsilon$, the investor solves

$$
\max _{\lambda_{2}} E_{\tilde{\gamma}}\left\{U\left((1+r)\left[(1+r) s_{1}^{*}+p_{2}\left(\lambda_{1}^{*}-\lambda_{2}\right)\right]+\lambda_{2}(\tilde{\gamma}+\varepsilon)\right)\right\}
$$

The first order condition

$$
E_{\tilde{\gamma}}\left\{U^{\prime}(c)\left[-(1+r) p_{2}+(\tilde{\gamma}+\varepsilon)\right]\right\}=0
$$

implies $^{12}$

$$
p_{2}^{*}(\varepsilon)=\frac{E_{\tilde{\gamma}}\left\{U^{\prime}(c)(\tilde{\gamma}+\varepsilon)\right\}}{E_{\tilde{\gamma}}\left\{U^{\prime}(c)\right\}(1+r)} .
$$

Note that the expectation is taken only with respect to $\tilde{\gamma}$ - the uncertainty that remains unresolved until time 3-since $\varepsilon$ has already been observed at time 2 .

Since all agents behave rationally in this benchmark case, in equilibrium market clearing implies $s_{1}^{*}=e$ has to hold in the bond market, and $\lambda_{1}^{*}=\lambda_{2}^{*}=1$ has to hold in the

\footnotetext{
${ }^{12}$ Henceforth we will denote efficient prices by $\mathrm{p}^{*}$. These are the market clearing prices when (almost) all agents heed the information signal $\varepsilon$ revealed at time 1 and act rationally upon that information.
} 
stock market. Hence by (2) the equality $s_{2}^{*}=(1+r) s_{1}^{*}$ is satisfied. The equilibrium stock price at time 2 is thus

$$
p_{2}^{*}(\varepsilon)=\frac{E_{\tilde{\gamma}}\left\{U^{\prime}(c)(\tilde{\gamma}+\varepsilon)\right\}}{E_{\tilde{\gamma}}\left\{U^{\prime}(c)\right\}(1+r)}=\frac{1}{1+r}\left[\varepsilon+E\{\tilde{\gamma}\}+\frac{\operatorname{cov}\left[U^{\prime}(c), \tilde{\gamma}\right]}{E_{\tilde{\gamma}}\left\{U^{\prime}(c)\right\}}\right]
$$

with $c=(1+r)^{2} e+\tilde{\gamma}+\varepsilon$.

Stage II: Working backward to period 1, each agent chooses an initial portfolio subject to the expectation of the equilibrium price function at time $2, p_{2}^{*}(\varepsilon)$, by solving the problem

$$
\begin{gathered}
\max _{s_{1}, \lambda_{1}} E_{\tilde{\gamma}, \widetilde{\varepsilon}}\left\{U\left((1+r)^{2} s_{1}+(1+r) p_{2}^{*}(\widetilde{\varepsilon})\left(\lambda_{1}-1\right)+(\tilde{\gamma}+\widetilde{\varepsilon})\right)\right\} \\
\text { s.t. } \quad e+p_{1}=s_{1}+p_{1} \lambda_{1}
\end{gathered}
$$

where expectations are taken with respect to $\tilde{\gamma}$ and $\tilde{\varepsilon}$. The first-order condition for a maximum,

$$
E_{\tilde{\gamma}, \tilde{\varepsilon}}\left\{U^{\prime}(c)\left[-(1+r)^{2} p_{1}+(1+r) p_{2}^{*}(\widetilde{\varepsilon})\right]\right\}=0,
$$

implies the equilibrium equity price at time 1 :

$$
p_{1}^{*}=\frac{E_{\tilde{\gamma}, \tilde{\varepsilon}}\left\{U^{\prime}(c) p_{2}^{*}(\tilde{\varepsilon})\right\}}{E_{\tilde{\gamma}, \tilde{\varepsilon}}\left\{U^{\prime}(c)\right\}(1+r)}=\frac{E\left\{p_{2}^{*}(\tilde{\varepsilon})\right\}}{1+r}+\frac{\operatorname{cov}\left[U^{\prime}(c), p_{2}^{*}(\tilde{\varepsilon})\right]}{E_{\tilde{\gamma}, \tilde{\varepsilon}}\left\{U^{\prime}(c)\right\}(1+r)} .
$$

The stock price at time 1 is lower than the discounted expected stock price at time 2, since $\operatorname{cov}\left[U^{\prime}(c), p_{2}^{*}(\tilde{\varepsilon})\right]$ is negative.

\section{B. Benchmark Case 2: All Investors Ignore the Information Signal}

Again we proceed backward in time. Suppose a typical investor has chosen an initial portfolio $\left(s_{1}^{D}, \lambda_{1}^{D}\right)$ at date 1 (of course, in equilibrium $s_{1}^{D}=e$ and $\lambda_{1}^{D}=1$ because all investors hold the same portfolio at that time). ${ }^{13}$ At the beginning of time 2 , the signal $\varepsilon$ is revealed, but the investor decides to ignore the information and solves

$$
\max _{\lambda_{2}} E_{\tilde{\gamma}, \tilde{\varepsilon}}\left\{U\left((1+r)\left[(1+r) s_{1}^{D}+p_{2}\left(\lambda_{1}^{D}-\lambda_{2}\right)\right]+\lambda_{2}(\tilde{\gamma}+\tilde{\varepsilon})\right)\right\}
$$

\footnotetext{
${ }^{13}$ The superscript ' $D$ ' stands for 'disregarding the information', ' $H$ ' will stand for 'heeding the information.'
} 
The first-order condition implies an equity price of

$$
p_{2}^{D}(\varepsilon)=\bar{p}=\frac{E_{\tilde{\gamma}, \tilde{\varepsilon}}\left\{U^{\prime}(c)(\tilde{\gamma}+\widetilde{\varepsilon})\right\}}{E_{\tilde{\gamma}, \tilde{\varepsilon}}\left\{U^{\prime}(c)\right\}(1+r)},
$$

with $c=(1+r)^{2} e+\tilde{\gamma}+\widetilde{\varepsilon}$.

Since no new information enters into the individual portfolio decision between time 1 and time $2, p_{1}^{D}=\bar{p}$ holds.

\section{Asset Pricing With Cognitive Dissonance}

We now turn to modeling how each investor individually decides whether or not to heed the information signal-and thus whether to act rationally or quasirationally. This decision is modeled as follows: if the investor achieves a higher expected utility at time 2 by ignoring the signal, he will choose to do so; otherwise he will rationally use the information provided by the signal.

Suppose an investor heeds the information $\varepsilon$ and observes the asset price $p$ at time 2. ${ }^{14}$ In equilibrium, all investors hold the same asset portfolio at date 1 consisting of $e$ bonds and one share, i.e. $\mathrm{s}_{1}=e, \lambda_{1}=1$. Let the full-information value function at time $2, \Psi(p, \varepsilon)$, be defined by

$$
\Psi(p, \varepsilon):=\max _{\lambda_{2}} E_{\tilde{\gamma}}\left\{U\left((1+r)\left[(1+r) e+p\left(1-\lambda_{2}\right)\right]+\lambda_{2}(\tilde{\gamma}+\varepsilon)\right)\right\}
$$

and denote the solution to the problem by $\lambda_{2}^{H}(p, \varepsilon)$; it is the per-capita demand for the risky asset when the information $\varepsilon$ is heeded.

By contrast, suppose the investor ignores the information $\varepsilon$ but observes the asset price $p$. In this case, let $\Phi(p)$ denote the no-information value function, which is defined as

$$
\Phi(p):=\max _{\lambda_{2}} E_{\tilde{\gamma}, \tilde{\varepsilon}}\left\{U\left((1+r)\left[(1+r) e+p\left(1-\lambda_{2}\right)\right]+\lambda_{2}(\tilde{\gamma}+\tilde{\varepsilon})\right)\right\}
$$

It is the maximum expected utility at price $p$ when the signal is ignored. The demand for the risky asset in period 2 is in this case denoted by $\lambda_{2}^{D}(p)$.

\footnotetext{
${ }^{14}$ From now on we will suppress the time subscript, since the subsequent analysis focuses exclusively on the asset price at time 2 after market participants have received potentially new information.
} 
Formally, for a given signal $\varepsilon$, an investor faces cognitive dissonance and will choose to ignore the information $\varepsilon$ if and only if

$$
\Phi(p)>\Psi(p, \varepsilon)
$$

We can now define the Nash equilibria in this model.

Definition 1 (equilibria in pure or mixed strategies): Consider a realization of the signal $\varepsilon^{\prime}$.

a) $\left\{\lambda_{2}^{H}\left(p^{*}\left(\varepsilon^{\prime}\right), \varepsilon^{\prime}\right), p^{*}\left(\varepsilon^{\prime}\right)\right\}$ is a pure-strategy full-information equilibrium at $\varepsilon^{\prime}$ if

(i) $p^{*}\left(\varepsilon^{\prime}\right)$ is such that $\lambda_{2}^{H}\left(p^{*}\left(\varepsilon^{\prime}\right), \varepsilon^{\prime}\right)=1$;

(ii) $\Psi\left(p^{*}\left(\varepsilon^{\prime}\right), \varepsilon^{\prime}\right) \geq \Phi\left(p^{*}\left(\varepsilon^{\prime}\right)\right)$.

b) $\left\{\lambda_{2}^{D}(\bar{p}), \bar{p}\right\}$ is a pure-strategy no-information equilibrium at $\varepsilon^{\prime}$ if

(i) $\bar{p}$ is such that $\lambda_{2}^{D}(\bar{p})=1$;

(ii) $\Phi(\bar{p}) \geq \Psi\left(\bar{p}, \varepsilon^{\prime}\right)$.

c) $\left\{\lambda_{2}^{H}\left(\hat{p}\left(\varepsilon^{\prime}\right), \varepsilon^{\prime}\right), \lambda_{2}^{D}\left(\hat{p}\left(\varepsilon^{\prime}\right)\right), \hat{p}\left(\varepsilon^{\prime}\right)\right\}$ is a mixed-strategy equilibrium at $\varepsilon^{\prime}$ if

(i) $\exists \mu \in(0,1)$ such that $\mu \lambda_{2}^{H}\left(\hat{p}\left(\varepsilon^{\prime}\right), \varepsilon^{\prime}\right)+(1-\mu) \lambda_{2}^{D}\left(\hat{p}\left(\varepsilon^{\prime}\right)\right)=1$

(ii) $\Psi\left(\hat{p}\left(\varepsilon^{\prime}\right), \varepsilon^{\prime}\right)=\Phi\left(\hat{p}\left(\varepsilon^{\prime}\right)\right)$.

The conditions (ii) in parts (a), (b), and (c) of Definition 1 ensure that, in equilibrium, an agent will not ignore (heed) the signal if he can achieve a higher welfare by heeding (ignoring) the information.

Before we can characterize the equilibria, a few useful properties of the value functions need to be derived (see Figure 1).

Proposition 1 The value functions $\Psi$ (.) and $\Phi$ (.) have the following properties:

1. Let $p^{*}(\varepsilon)$ be a pure-strategy equilibrium equity price for the realization $\varepsilon$ and assume that all agents heed the information. Then, as a function of $p$, the fullinformation value function, $\Psi(p, \varepsilon)$, possesses a global minimum at $p=p^{*}(\varepsilon)$ and is strictly monotone on the intervals $\left(-\infty, p^{*}(\varepsilon)\right)$ and $\left(p^{*}(\varepsilon), \infty\right)$.

2. Let $\bar{p}$ be a pure-strategy equilibrium asset price when all agents ignore the information $\varepsilon$. Then the no-information value function $\Phi(p)$ has a global minimum at $p=\bar{p}$ and is strictly monotone on the intervals $(-\infty, \bar{p})$ and $(\bar{p}, \infty)$.

Proof: Suppose without loss of generality that the agents observe the signal $\varepsilon$ (if the signal is ignored, the same result is obtained by a symmetric argument). 
Step 1: $\lambda_{2}^{H}$ satisfies the first-order condition

$$
E_{\tilde{\gamma}}\left\{U^{\prime}(\cdot)\left[-(1+r) p^{*}(\varepsilon)+(\tilde{\gamma}+\varepsilon)\right]\right\}=0
$$

from which we derive

$$
\begin{aligned}
\left.\frac{\partial \lambda_{2}^{H}}{\partial p}\right|_{p=p^{*}(\varepsilon)} & =\frac{E_{\tilde{\gamma}}\left\{U^{\prime \prime}(\cdot)(1+r)\left(1-\lambda_{2}^{H}\right)\left[-(1+r) p^{*}(\varepsilon)+(\tilde{\gamma}+\varepsilon)\right]+(1+r) U^{\prime}(\cdot)\right\}}{E_{\tilde{\gamma}}\left\{U^{\prime \prime}(\cdot)\left[\tilde{\gamma}+\varepsilon-p^{*}(\varepsilon)(1+r)\right]^{2}\right\}} \\
& =\frac{(1+r) E_{\tilde{\gamma}}\left\{U^{\prime}(\cdot)\right\}}{E_{\tilde{\gamma}}\left\{U^{\prime \prime}(\cdot)\left[\tilde{\gamma}+\varepsilon-p^{*}(\varepsilon)(1+r)\right]^{2}\right\}}<0,
\end{aligned}
$$

since $\lambda_{2}^{H}=1$ holds in equilibrium. In fact, the above inequality is valid for any $p$ that satisfies $\lambda_{2}^{H}(p, \varepsilon)=1$. Thus we conclude

$$
\lambda_{2}^{H}(p, \varepsilon)>(<) 1 \Leftrightarrow p<(>) p^{*}(\varepsilon)
$$

Step 2: Differentiation of the full-information value function with respect to $p$ yields

$$
\frac{\partial \Psi(p, \varepsilon)}{\partial p}=E_{\tilde{\gamma}}\left\{U^{\prime}(\cdot)(1+r)\left[1-\lambda_{2}^{H}(p, \varepsilon)\right]\right\}
$$

Combining (13) and (14), we get

$$
\frac{\partial \Psi(p, \varepsilon)}{\partial p}\left\{\begin{array}{l}
<0 ; p<p^{*}(\varepsilon) \\
=0 ; p=p^{*}(\varepsilon) \\
>0 ; p>p^{*}(\varepsilon)
\end{array}\right.
$$

which proves the claim.

QED.

To simplify the characterization of the equilibrium equity price function at time 2, we now assume that $\widetilde{\gamma}$ and $\widetilde{\varepsilon}$ have a multivariate normal distribution. Recall that individual preferences are $U(c)=-\exp (-\beta c)$ and that in equilibrium all investors hold the same asset portfolio at time $1,\left(s_{1}, \lambda_{1}\right)=(e, 1)$. Thus, if an investor observes the signal $\varepsilon$, his expected utility at time 2 is

$$
\begin{aligned}
E_{\tilde{\gamma}} & \{U(c)\}=E_{\tilde{\gamma}}\left\{U\left([1+r] s_{2}+[\tilde{\gamma}+\varepsilon] \lambda_{2}\right)\right\} \\
\quad & =-\exp \left(-\beta\left[(1+r) s_{2}+\lambda_{2}(\varepsilon+E\{\tilde{\gamma}\})-\frac{\beta}{2}\left(\lambda_{2}\right)^{2} \sigma_{\gamma}\right]\right)
\end{aligned}
$$




$$
=-\exp \left(-\beta\left[\bar{e}+(1+r) p+\lambda_{2}(\varepsilon+E\{\tilde{\gamma}\}-(1+r) p)-\frac{\beta}{2}\left(\lambda_{2}\right)^{2} \sigma_{\gamma}\right]\right)
$$

where $\sigma_{\gamma}:=\operatorname{var}(\tilde{\gamma})$ and $\bar{e}:=(1+r)^{2} e$. If the agent does not heed the signal $\varepsilon$, his perceived expected utility at time 2 is

$$
E_{\tilde{\gamma}, \tilde{\varepsilon}}\{U(c)\}=-\exp \left(-\beta\left[\bar{e}+(1+r) p+\lambda_{2}(E\{\tilde{\gamma}\}-(1+r) p)-\frac{\beta}{2}\left(\lambda_{2}\right)^{2}\left(\sigma_{\gamma}+\sigma_{\varepsilon}\right)\right]\right)
$$

where $\sigma_{\varepsilon}:=\operatorname{var}(\tilde{\varepsilon})$. The first-order necessary conditions are

$$
\varepsilon+E\{\tilde{\gamma}\}-(1+r) p=\beta \lambda_{2} \sigma_{\gamma}
$$

and

$$
E\{\tilde{\gamma}\}-(1+r) p=\beta \lambda_{2}\left(\sigma_{\gamma}+\sigma_{\varepsilon}\right)
$$

Thus, desired equity holdings as a function of the equity price are

$$
\lambda_{2}^{H}(\varepsilon, p)=\frac{\varepsilon+E\{\tilde{\gamma}\}-(1+r) p}{\beta \sigma_{\gamma}}
$$

when the information is heeded, and

$$
\lambda_{2}^{D}(p)=\frac{E\{\tilde{\gamma}\}-(1+r) p}{\beta\left(\sigma_{\gamma}+\sigma_{\varepsilon}\right)}
$$

when the information is ignored.

\section{How Information Affects Asset Prices}

Having derived investors' asset demand functions, we can now investigate how equity prices respond to new information. The key results are presented by an equity price function that describes how the price depends on the realization of the signal $\varepsilon$. The shape of this function will differ for various regions of the realization of the signal. Each region, it turns out, is characterized by a specific price formation process resulting from the way in which investors treat the new information (Figure 2). 


\section{A. Full-Information Equilibria: All Investors Heed the Information}

To find the set of realizations of the signal for which investors heed the information, we proceed as follows. After inserting the market clearing condition $\lambda_{2}^{H}=1$ into equation (19), the equilibrium equity price at time 2 if (almost) all agents heed the information (i.e., the efficient share price $p^{*}(\varepsilon)$ ) is a (linear) function of the information $\varepsilon$,

$$
p^{*}(\varepsilon)=\frac{\varepsilon+E\{\tilde{\gamma}\}-\beta \sigma_{\gamma}}{1+r} .
$$

Suppose the signal indicates $\varepsilon=0$, and the shares are valued efficiently at $p^{*}(0)$. Then each investor will heed the information, because $c^{D}=(1+r) s_{2}+(\tilde{\gamma}+\widetilde{\varepsilon}) \lambda_{2}$ is dominated by $c^{H}=(1+r) s_{2}+\tilde{\gamma} \lambda_{2}$ in the sense of Second Order Stochastic Dominance for all $\left(\lambda_{2}, s_{2}\right)$, implying that the maximum value of (15) is larger than the maximum value of (16) (recall that $\tilde{\gamma}$ and $\widetilde{\varepsilon}$ are stochastically independent). Thus the market clears at the efficient price $p^{*}(0)$.

Next, we compute the thresholds $\varepsilon_{1}$ and $\varepsilon_{0}$-the endpoints of the full-information interval-where agents start to dismiss the new information and deviate from fully rational behavior. Let $\varepsilon$ ' be a realization of $\widetilde{\varepsilon}$ such that an agent is indifferent between heeding and disregarding the information $\varepsilon^{\prime}$, if the shares are valued efficiently, i.e, $p\left(\varepsilon^{\prime}\right)=p^{*}\left(\varepsilon^{\prime}\right)$. To determine the value(s) of $\varepsilon^{\prime}$, note that an agent's expected utility is

$$
-\exp \left(-\beta\left[\bar{e}+(1+r) p+\frac{[\varepsilon+E\{\tilde{\gamma}\}-(1+r) p]^{2}}{2 \beta \sigma_{\gamma}}\right]\right),
$$

if the agent heeds the information, while the expected utility is

$$
-\exp \left(-\beta\left[\bar{e}+(1+r) p+\frac{[E\{\tilde{\gamma}\}-(1+r) p]^{2}}{2 \beta\left(\sigma_{\gamma}+\sigma_{\varepsilon}\right)}\right]\right),
$$

if the information is ignored. At $\varepsilon^{\prime},(22)$ and (23) must be equal under efficient asset pricing, which implies

$$
\left(\sigma_{\gamma}+\sigma_{\varepsilon}\right)\left[\varepsilon^{\prime}+E\{\tilde{\gamma}\}-(1+r) p^{*}\left(\varepsilon^{\prime}\right)\right]^{2}=\sigma_{\gamma}\left[E\{\tilde{\gamma}\}-(1+r) p^{*}\left(\varepsilon^{\prime}\right)\right]^{2}
$$

Using (17), we obtain

$$
E\{\tilde{\gamma}\}-(1+r) p^{*}\left(\varepsilon^{\prime}\right)=\beta \sigma_{\gamma}-\varepsilon^{\prime}
$$

Equation (24) then becomes 


$$
\left(\sigma_{\gamma}+\sigma_{\varepsilon}\right) \beta^{2} \sigma_{\gamma}=\left(\beta \sigma_{\gamma}-\varepsilon^{\prime}\right)^{2}
$$

Thus, if we denote the negative solution to the last equation by $\varepsilon_{1}$ and the positive solution by $\varepsilon_{0}$, we obtain

$$
\varepsilon_{1}=\beta \sigma_{\gamma}\left[1-\sqrt{1+\frac{\sigma_{\varepsilon}}{\sigma_{\gamma}}}\right] ; \quad \varepsilon_{0}=\beta \sigma_{\gamma}\left[1+\sqrt{1+\frac{\sigma_{\varepsilon}}{\sigma_{\gamma}}}\right]
$$

In the interval $\left[\varepsilon_{1}, \varepsilon_{0}\right]$, which includes the ex ante expected value $\varepsilon=0$, investors use all available information and equities are thus priced efficiently (see Figure 2).

Proposition 2. For any realization $\varepsilon \in\left[\varepsilon_{1}, \varepsilon_{0}\right]$, there exists a unique full-information equilibrium (type (a) in Definition 1) such that all agents heed the signal. By (21), the equilibrium equity price is the efficient price

$$
p(\varepsilon)=\frac{\varepsilon+E\{\tilde{\gamma}\}-\beta \sigma_{\gamma}}{1+r} .
$$

Proof: First note that according to (21), the efficient pricing function $p^{*}(\varepsilon)$ has slope $1 /(1+r)$

$$
\frac{\partial p^{*}(\varepsilon)}{\partial \varepsilon}=\frac{1}{1+r}
$$

Step 1: By definition, $\varepsilon_{0}$ and $\varepsilon_{1}$ satisfy the condition that the no-information value function and the full-information value function assume the same values at the price $p^{*}(\varepsilon)$; i.e.

$$
\begin{aligned}
\Phi\left(p^{*}(\varepsilon)\right): & =E_{\tilde{\gamma}, \tilde{\varepsilon}}\left\{-\exp \left(-\beta\left\{\bar{e}+p^{*}(\varepsilon)(1+r)\left[1-\lambda_{2}^{D}\left(p^{*}(\varepsilon)\right)\right]+\lambda_{2}^{D}\left(p^{*}(\varepsilon)\right)(\tilde{\gamma}+\tilde{\varepsilon})\right\}\right)\right\} \\
& =E_{\tilde{\gamma}}\{-\exp (-\beta[\bar{e}+\tilde{\gamma}+\tilde{\varepsilon}])\}=: \Psi\left(p^{*}(\varepsilon), \varepsilon\right)
\end{aligned}
$$

and $\Phi\left(p^{*}(\varepsilon)\right) \neq \Psi\left(p^{*}(\varepsilon), \varepsilon\right)$ holds $\forall \varepsilon \in\left(\varepsilon_{1}, \varepsilon_{0}\right)$. If we can show that the equality in (27) implies

$$
\left.\frac{\partial \Phi\left(p^{*}(\varepsilon)\right)}{\partial \varepsilon}\right|_{\varepsilon=\varepsilon_{1}}<\left.\frac{\partial \Psi\left(p^{*}(\varepsilon), \varepsilon\right)}{\partial \varepsilon}\right|_{\varepsilon=\varepsilon_{1}}
$$

then $\Psi\left(p^{*}(\varepsilon), \varepsilon\right)>\Phi\left(p^{*}(\varepsilon)\right)$ follows for all $\varepsilon \in\left(\varepsilon_{1}, \varepsilon_{0}\right)$ by a simple continuity argument. In other words, given the price $p^{*}(\varepsilon)$, the expected utility of an agent who ignores the signal, $\Phi\left(p^{*}(\varepsilon)\right)$, would be smaller than the expected utility of an agent who heeds the information, 
$\Psi\left(p^{*}(\varepsilon), \varepsilon\right)$, for $\varepsilon \in\left(\varepsilon_{1}, \varepsilon_{0}\right)$. Thus, $p(\varepsilon):=p^{*}(\varepsilon)$ would be an equilibrium price and all agents would heed the signal, as is claimed in the proposition. Since $\lambda_{2}^{D}\left(p^{*}\left(\varepsilon_{1}\right)\right)$ is strictly positive by equations (20), (21) and (25), the equality $\Phi\left(p^{*}\left(\varepsilon_{1}\right)\right)=\Psi\left(p^{*}\left(\varepsilon_{1}\right), \varepsilon_{1}\right)$ implies

$$
\begin{aligned}
\left.\frac{\partial \Phi\left(p^{*}(\varepsilon)\right)}{\partial \varepsilon}\right|_{\varepsilon=\varepsilon_{1}} & =-\Phi\left(p^{*}\left(\varepsilon_{1}\right)\right) \beta p^{* \prime}\left(\varepsilon_{1}\right)(1+r)\left[1-\lambda_{2}^{D}\left(p *\left(\varepsilon_{1}\right)\right)\right] \\
& \left.=-\Phi\left(p^{*}\left(\varepsilon_{1}\right)\right) \beta \mid 1-\lambda_{2}^{D}\left(p^{*}\left(\varepsilon_{1}\right)\right)\right] \\
& <-\Psi\left(p *\left(\varepsilon_{1}\right), \varepsilon_{1}\right) \beta=\left.\frac{\partial \Psi(p *(\varepsilon), \varepsilon)}{\partial \varepsilon}\right|_{\varepsilon=\varepsilon_{1}}
\end{aligned}
$$

which remained to be shown. In the second equality we used the relation (26).

Step 2 (uniqueness): By (19) and (20), both asset demands $\lambda_{2}^{H}(\varepsilon, p)$ and $\lambda_{2}^{D}(p)$ are strictly monotone decreasing in the asset price $p$. Furthermore, $1=\lambda_{2}^{H}\left(\varepsilon, p^{*}(\varepsilon)\right)=\lambda_{2}^{D}(\bar{p})$, where $\bar{p}:=\frac{1}{1+r}\left[E\{\tilde{\gamma}\}-\beta\left(\sigma_{\gamma}+\sigma_{\varepsilon}\right)\right]$ is the equilibrium equity price if all investors ignore the information. It is easy to check that $\bar{p}<p^{*}(\varepsilon)$ for $\varepsilon \in\left[\varepsilon_{1}, \varepsilon_{0}\right]$. Thus, any price above $p^{*}(\varepsilon)$ or below $\bar{p}$ cannot be an equilibrium price as the demand for stocks in period 2 would either be less than 1 or exceed 1 for all agents. A price $p$ such that $\bar{p} \leq p<p^{*}(\varepsilon)$ cannot be an equilibrium price either because it would imply, by Proposition 1 , that the expected utility of agents who heed the signal is higher than $\Psi\left(p^{*}(\varepsilon), \varepsilon\right)$, and the expected utility of agents who ignore the signal is smaller than $\Phi\left(p^{*}(\varepsilon)\right)$.

Q.E.D.

\section{B. Slightly Less Favorable Information Is Ignored by Some Investors}

For signals that are slightly less favorable than those in the full-information region, some agents ignore the information, while others heed it. As a result, the equity price reacts more strongly to the signal than under full information. Suppose all agents ignore the information signal $\varepsilon$. Market clearing requires $\lambda_{2}^{D}(p)=1$, and (20) implies the market clearing stock price

$$
\bar{p}:=\frac{1}{1+r}\left[E\{\tilde{\gamma}\}-\beta\left(\sigma_{\gamma}+\sigma_{\varepsilon}\right)\right] .
$$

Let $\varepsilon$ " be a realization of $\widetilde{\varepsilon}$ such that an agent is indifferent between heeding and ignoring the information $\varepsilon$ ”, if shares are valued at $\bar{p}$. Equating (22) and (23), using the definition of $\bar{p}$ and solving for $\varepsilon$ ”, gives two solutions 


$$
\varepsilon_{2}=-\beta\left(\sigma_{\gamma}+\sigma_{\varepsilon}\right)\left[1-\sqrt{\frac{\sigma_{\gamma}}{\sigma_{\gamma}+\sigma_{\varepsilon}}}\right]
$$

and

$$
\varepsilon_{3}=-\beta\left(\sigma_{\gamma}+\sigma_{\varepsilon}\right)\left[1+\sqrt{\frac{\sigma_{\gamma}}{\sigma_{\gamma}+\sigma_{\varepsilon}}}\right] \text {. }
$$

For signals in the interval $\left(\varepsilon_{2}, \varepsilon_{1}\right)$ (see Figure 2), a pure-strategy Nash equilibrium does not exist because both $\Psi\left(p^{*}(\varepsilon), \varepsilon\right)<\Phi\left(p^{*}(\varepsilon)\right)$ and $\Psi(\bar{p}, \varepsilon)>\Phi(\bar{p})$ hold simultaneously. In other words, if all other agents behaved rationally, then ignoring the signal would be an optimal response, while it would be optimal for an investor to heed the information if all other agents ignored it. Mixed-strategy Nash equilibria, however, exist where one group of investors heeds the signal $\varepsilon$, while another group ignores the information (equilibria of type (c) in Definition 1 ), so that there is a unique market-clearing price $\hat{p}\left(\varepsilon^{\prime}\right)$ for $\varepsilon^{\prime} \in\left(\varepsilon_{2}, \varepsilon_{1}\right)$ at which investors are indifferent between ignoring the information and heeding it (see point A in Figure 1 where $\Psi\left(\hat{p}\left(\varepsilon^{\prime}\right), \varepsilon^{\prime}\right)=\Phi\left(\hat{p}\left(\varepsilon^{\prime}\right)\right)$ holds). For investors who observe $\varepsilon^{\prime}$, equities look relatively cheap at the price $\hat{p}\left(\varepsilon^{\prime}\right)$ (since $\hat{p}\left(\varepsilon^{\prime}\right)<p^{*}\left(\varepsilon^{\prime}\right)$ ), hence they hold more than one share. Investors who ignore the information $\varepsilon^{\prime}$ hold less than one share. The equilibrium fraction of investors who ignore the information is thus endogenously determined to achieve market clearing.

These mixed-strategy equilibria are stable. Denote the equilibrium fraction of agents who ignore $\varepsilon^{\prime}$ by $\mu\left(\varepsilon^{\prime}\right)$. Suppose that initially more than $\mu\left(\varepsilon^{\prime}\right)$ agents ignore $\varepsilon^{\prime}$. Do agents who initially heeded the information now have an incentive to ignore $\varepsilon$, so that the system would move further away from the equilibrium fraction $\mu\left(\varepsilon^{\prime}\right)$ ? Or do agents who initially ignored the information now have an incentive to heed $\varepsilon^{\prime}$ ? If more than $\mu\left(\varepsilon^{\prime}\right)$ investors ignore $\varepsilon^{\prime}$, the market clearing price will be $p^{\prime}<\hat{p}\left(\varepsilon^{\prime}\right)$. At $p^{\prime}$ (see points B and C in Figure 1), agents are better off heeding $\varepsilon^{\prime}$. Thus the out-of-equilibrium dynamics would lead back to the equilibrium fraction $\mu\left(\varepsilon^{\prime}\right)$, making the mixed-strategy equilibrium stable. ${ }^{15}$

For any $\varepsilon \in\left(\varepsilon_{2}, \varepsilon_{1}\right)$, the equilibrium price is such that agents are indifferent between heeding $\varepsilon$ and ignoring it; i.e., the equilibrium price $\hat{p}(\varepsilon)$ in this region is such that

$$
\left(\sigma_{\gamma}+\sigma_{\varepsilon}\right)[\varepsilon+E\{\tilde{\gamma}\}-(1+r) \hat{p}(\varepsilon)]^{2}=\sigma_{\gamma}[E\{\tilde{\gamma}\}-(1+r) \hat{p}(\varepsilon)]^{2}
$$

${ }^{15}$ According to Figure 1, there is another asset price $p^{\prime \prime}\left(\varepsilon^{\prime}\right)$ such that $\Psi\left(p^{\prime \prime}\left(\varepsilon^{\prime}\right), \varepsilon^{\prime}\right)=\Phi\left(p^{\prime \prime}\left(\varepsilon^{\prime}\right)\right)$. But $p^{\prime \prime}\left(\varepsilon^{\prime}\right)>\hat{p}\left(\varepsilon^{\prime}\right)>\bar{p}$, thus the per-capita asset demand at the price $p^{\prime \prime}\left(\varepsilon^{\prime}\right)$ is less than 1 for both groups of agents, contradicting market clearing. 
holds. Differentiation of (30) yields

$$
\frac{\partial \hat{p}(\varepsilon)}{\partial \varepsilon}=\frac{1}{1+r}\left[1-\frac{[E\{\tilde{\gamma}\}-(1+r) \hat{p}(\varepsilon)] \sigma_{\gamma}}{[\varepsilon+E\{\tilde{\gamma}\}-(1+r) \hat{p}(\varepsilon)]\left(\sigma_{\gamma}+\sigma_{\varepsilon}\right)}\right]^{-1} .
$$

Combining (30) and (31), we obtain

$$
\frac{\partial \hat{p}(\varepsilon)}{\partial \varepsilon}=\frac{1}{1+r}\left[1-\sqrt{\frac{\sigma_{\gamma}}{\sigma_{\gamma}+\sigma_{\varepsilon}}}\right]^{-1}>\frac{1}{1+r} .
$$

Thus, in the interval $\left(\varepsilon_{2}, \varepsilon_{1}\right)$, the equilibrium pricing function is given by $p(\varepsilon)=\hat{p}(\varepsilon)$. The function $\hat{p}(\varepsilon)$ is linear between $\varepsilon_{2}$ and $\varepsilon_{1}$, but steeper than the efficient price function in the interval $\left[\varepsilon_{1}, \varepsilon_{0}\right]$ (see Figure 2).

The equilibrium pricing function in this region is steeper than the efficient pricing function because agents who heed the signal find equities less risky than the agents who ignore the signal. As a consequence, they hold more shares in their portfolios, i.e., $\lambda_{2}^{H}>1$. Thus rational agents buy shares, and quasirational agents - those who ignore the information - sell shares. As a result, an increase in the stock price in this region of mixed strategies will hurt rational agents (whose share purchases become more expensive) and benefit quasirational agents. Fix some $\varepsilon$ in the mixed-strategy interval $\left[\varepsilon_{2}, \varepsilon_{1}\right]$. At the efficient price $p^{*}(\varepsilon)$, agents would prefer to ignore the information. Thus a lower price than $p^{*}(\varepsilon)$ is needed to equate the welfare of rational and quasirational investors. Critical for this argument is the fact that, at a price between $\bar{p}$ and $p^{*}(\varepsilon)$, rational agents hold more shares in their portfolios than quasirational agents. Quasirational investors face a more uncertain environment and thus prefer relatively safe asset portfolios.

\section{Sufficiently Bad News Is Ignored by All Investors}

Signals in the interval $\left[\varepsilon_{3}, \varepsilon_{2}\right]$, which are less favorable than signals that lead to mixed strategies, will be ignored by all agents, since $\Phi(\bar{p}) \geq \Psi(\bar{p}, \varepsilon)$ holds. By an argument symmetric to the one used in Section IV.A, $p(\varepsilon)=\bar{p}$ (defined in (29)) is the unique equilibrium price for any realization of $\varepsilon \in\left[\varepsilon_{3}, \varepsilon_{2}\right]$. At $\varepsilon_{3}$ agents are again indifferent between ignoring the information and heeding it. The efficient pricing function $p^{*}(\varepsilon)$ intersects the equilibrium price $p^{*}(\hat{\varepsilon})=\bar{p}$ at $\hat{\varepsilon}:=-\beta \sigma_{\varepsilon}$. For $\varepsilon>\hat{\varepsilon}$, equities are undervalued, and for $\varepsilon<\hat{\varepsilon}$ equities are overvalued relative to the price in an efficient market (see Figure 2). 


\section{Highly Unfavorable and Highly Favorable News is Heeded by Some Investors and Ignored by Others}

Consider the interval $\left(-\infty, \varepsilon_{3}\right)$, which reflects extremely unfavorable news, and the interval $\left(\varepsilon_{0}, \infty\right)$, which reflects very good news. In these regions, pure-strategy Nash equilibria do not exist since $\Psi\left(p^{*}(\varepsilon), \varepsilon\right)<\Phi\left(p^{*}(\varepsilon)\right)$ and $\Psi(\bar{p}, \varepsilon)>\Phi(\bar{p})$ holds for all $\varepsilon \in\left(-\infty, \varepsilon_{3}\right) \cup\left(\varepsilon_{0}, \infty\right)$. But there are mixed-strategy equilibria such that some investors heed the information while others ignore it. The unique equilibrium price that supports a mixedstrategy Nash equilibrium for a given $\varepsilon$-realization equates the welfare of rational and quasirational agents. Applying the same procedure as in Section IV.B yields

$$
\frac{\partial p(\varepsilon)}{\partial \varepsilon}=\frac{1}{1+r}\left[1+\sqrt{\frac{\sigma_{\gamma}}{\sigma_{\gamma}+\sigma_{\varepsilon}}}\right]^{-1}<\frac{1}{1+r}
$$

for $\varepsilon \in\left(-\infty, \varepsilon_{3}\right) \cup\left(\varepsilon_{0}, \infty\right)$.

For very unfavorable information, i.e. $\varepsilon<\varepsilon_{3}$, shares are overvalued relative to the efficient price $p^{*}(\varepsilon)$ (see Figure 2). Agents who heed the information therefore sell equities short and hold larger short positions the smaller is the observed $\varepsilon$-realization. The efficient price, $p *(\varepsilon)$, is smaller than $\bar{p}$, otherwise rational investors would hold more than 1 share at $\left(\varepsilon_{3}, \bar{p}\right)$ rather than a negative amount.

For realizations that are less favorable than $\varepsilon_{3}$ (recall that at $\varepsilon_{3}$ all investors ignore the signal), some agents will begin to heed the information. For sufficiently unfavorable information, the equity price distortions are large enough so that the extra profit gained by rational agents compensates them for their psychological conflict: the expected utility at date 2 of rational agents (despite taking the bad information into account) is equal to the expected utility of the naïve agents who ignore $\varepsilon$. Ex post (at date 3), the agents who heed the information are on average better off than the naïve agents (abstracting from their disutility caused by cognitive dissonance). In other words, investors resolve the psychological tradeoff they face differently: those investors who ignore $\varepsilon$ are avoiding the disutility of cognitive conflict, but they forego the bigger average wealth at time 3 from acting rationally. By contrast, investors who heed the unfavorable information achieve higher expected utility at time 3 , which compensates them for the disutility of acknowledging unfavorable information.

The asset pricing process for very favorable news in the interval $\left(\varepsilon_{0}, \infty\right)$ lends itself to an analogous interpretation. Here shares are undervalued relative to the efficient price $p^{*}(\varepsilon)$ and quasirational investors who ignore the news take short positions in equities. Since these agents do not acknowledge the positive information, shares appear expensive from their perspective. Therefore they try to make arbitrage profits by selling shares short. 
Acknowledging the strongly positive signal $\varepsilon>\varepsilon_{0}$ would cause cognitive conflict because the signal would suggest that the portfolio chosen at time 1 contained too few shares.

\section{E. At Most Half of the Investors Heed Highly Favorable and Highly Unfavorable Information}

As $|\varepsilon|$ gets larger in the $\left(-\infty, \varepsilon_{3}\right)$ region - that is, as the news gets worse for worsethan-expected news - more agents will heed the information. Yet the share of rational agents is bounded above by $1 / 2$; i.e. most of the agents choose to ignore the information irrespective of how strongly the released information deviates from their ex ante predictions and regardless of the price distortions. The share $\alpha(\varepsilon)$ of rational traders is determined by

$$
\alpha(\varepsilon) \lambda_{2}^{H}(\varepsilon, p(\varepsilon))+[1-\alpha(\varepsilon)] \lambda_{2}^{D}(p(\varepsilon))=1
$$

Using (19), (20) and (33) in (34), $\alpha:=\lim _{|\varepsilon| \rightarrow \infty} \alpha(\varepsilon)$ can be calculated as

$$
\alpha=\left[1+\frac{1}{\sqrt{1-I}}\right]^{-1} \in\left(0, \frac{1}{2}\right)
$$

where $I:=\sigma_{\varepsilon} /\left(\sigma_{\varepsilon}+\sigma_{\gamma}\right)$ measures the information content of the signal $\varepsilon$. Paradoxically, the less informative is the signal, the more attention it will receive, i.e., the more agents will return eventually (as $|\varepsilon| \rightarrow \infty$ ) to a rational assessment of their portfolio.

Quasirational agents do not eventually disappear entirely from the market (for $|\varepsilon| \rightarrow \infty$ ) despite the fact that they are, in some sense, taken advantage of by the rational investors, because for extremely bad news price inefficiencies need to persist to induce some investors to heed the information. ${ }^{16}$ An investor has an incentive to behave rationally in the face of unfavorable information only if he can exploit the distorted price structure at the expense of quasirational investors. Thus equities cannot be valued efficiently for these information realizations since an efficient price would eliminate any incentive to hold rational beliefs in the face of extremely bad news.

The equilibrium pricing process can be summarized as follows (see Figure 2). The risky asset is efficiently priced if the information released at date 2 is sufficiently close to its ex ante expected value. The asset is undervalued (and the associated risk overvalued) if the realization of the signal is between $\hat{\varepsilon}$ and $\varepsilon_{1}$ or if it is larger than $\varepsilon_{0}$; and the asset is

${ }^{16}$ This result is akin to the information paradox emphasized by Grossman and Stiglitz (1980): if asset prices were perfectly efficient, no investor would have an incentive to collect and process information; but in that case asset prices could not be efficient. 
overvalued for signals less than $\hat{\varepsilon}$. Taking the efficient pricing function $p^{*}(\varepsilon)$ as a reference point and measuring the (local) price volatility by the derivative of the price function, there is excessive price volatility (sensitivity to news) between $\varepsilon_{2}$ and $\varepsilon_{1}$, the right amount of price volatility between $\varepsilon_{1}$ and $\varepsilon_{0}$, while for sufficiently bad news and sufficiently good news (signals below $\varepsilon_{2}$ or above $\varepsilon_{0}$ ) equity prices are excessively stable.

\section{THE Less INFORMATIVE THE SignAL, THE LARgER THE MisPRICING}

The general shape of the equilibrium pricing function with quasirational investors depends critically on the informativeness of the signal $\varepsilon$. Informativeness, $I$, is measured by the portion of the overall uncertainty, $\sigma:=\sigma_{\varepsilon}+\sigma_{\gamma}$, that is resolved at date 2-i.e., $I$ $:=\sigma_{\varepsilon} / \sigma$. By holding $\sigma_{\varepsilon}$ fixed while varying $\sigma_{\gamma}$, we can control for the information content of the signal. Since the efficient pricing function $p^{*}(\varepsilon)$ serves as a benchmark, we perturb the distribution of $\tilde{\gamma}$ in a way that leaves the position of $p^{*}(\varepsilon)$ unchanged. In view of (21), this implies

$$
\beta d \sigma_{\gamma}=d E\{\tilde{\gamma}\}
$$

We will increase the informativeness of the signal by decreasing $\sigma_{\gamma}$ according to the above perturbation, i.e., $d I=\left(\partial I / \partial \sigma_{\gamma}\right) d \sigma_{\gamma}$, which leaves not only $p^{*}(\varepsilon)$ unchanged but also the values of $\bar{p}$ and $\hat{\varepsilon}$. From (25) we derive

$$
\begin{aligned}
& -\frac{\partial \varepsilon_{2}}{\partial I}=\frac{\partial \varepsilon_{1}}{\partial I}=-\beta \frac{\sigma}{I}\left[1-\frac{1+(1-I)^{-1}}{2(1-I)^{-1 / 2}}\right]>0 \\
& -\frac{\partial \varepsilon_{3}}{\partial I}=\frac{\partial \varepsilon_{0}}{\partial I}=-\beta \frac{\sigma}{I}\left[1+\frac{1+(1-I)^{-1}}{2(1-I)^{-1 / 2}}\right]<0 .
\end{aligned}
$$

The first equality in (36) and (37), respectively, follows from the observation that $\varepsilon_{1}+\varepsilon_{2}=\hat{\varepsilon}=\varepsilon_{0}+\varepsilon_{3}$ and the fact that $\hat{\varepsilon}$ does not depend on the information content of the signal.

According to (36) and (37), as the signal becomes less informative, the undervaluation region, $\left(\hat{\varepsilon}, \varepsilon_{1}\right) \cup\left(\varepsilon_{0}, \infty\right)$, becomes smaller, and thus overpricing of risk becomes less likely. At the same time, the pricing function gets steeper in the interval between $\varepsilon_{2}$ and $\varepsilon_{1}$ so that the asset price becomes more volatile and more sensitive to news. In the limit, when the informativeness goes to zero, $\varepsilon_{0}$ tends to $\infty$, and both $\varepsilon_{2}$ and $\varepsilon_{1}$ approach $\hat{\varepsilon} / 2$ : 
$\left.\varepsilon_{2}\right|_{I \rightarrow 0}=\left.\varepsilon_{1}\right|_{I \rightarrow 0}=\lim _{\sigma_{\gamma} \rightarrow \infty} \beta\left[\frac{1-\left(1+\frac{\sigma_{\varepsilon}}{\sigma_{\gamma}}\right)^{1 / 2}}{\frac{1}{\sigma_{\lambda}}}\right]=\lim _{\sigma_{\gamma} \rightarrow \infty}-\frac{1}{2} \beta \sigma_{\varepsilon}\left(1+\frac{\sigma_{\varepsilon}}{\sigma_{\gamma}}\right)^{-1 / 2}=-\frac{1}{2} \beta \sigma_{\varepsilon}=\frac{1}{2} \hat{\varepsilon}$,

where the third equality follows from an application of L'Hôpital's rule.

With a large amount of unresolved uncertainty (i.e., in response to a nearly irrelevant signal), the equilibrium price function will be almost vertical in the neighborhood of $\hat{\varepsilon} / 2$ so that slightly less favorable information results in a sharp drop in the equity price from $p^{*}$ ( $\hat{\varepsilon} / 2$ ) to $\bar{p}$. This price drop occurs although the information signal eliminates only a very small fraction of the overall uncertainty about the asset payoffs and, in this sense, is almost uninformative. Note that a sharp price correction can only occur in a small part of the undervaluation region that borders on the efficient pricing region. Thus a correction in this model does not reflect a repricing of overpriced assets; rather equities will be undervalued after the correction, whereas they would be priced efficiently for just slightly more favorable information.

Turning to the sensitivity of the $\varepsilon_{3}$-threshold (where arbitrage starts and some investors begin to heed the signal), we find that the amount of negative news that is necessary to induce some investors to return to an accurate assessment becomes larger (i.e., $\varepsilon_{3}$ moves to the left), the less informative the signal is (see equation (37)). In other words, the region where every investor ignores the information becomes larger the less information is conveyed by the signal. This effect has a straightforward explanation: as the costs of neglecting the information (which vary positively with the information content) decline, investors are more prone to ignoring the information. In addition, if the information content of the signal is smaller, the equilibrium pricing function becomes flatter for realizations below $\varepsilon_{3}$. Thus, while the size of the overvaluation regime does not depend on the informativeness of the signal, the extent to which equities are overpriced on average in the overvaluation region strictly decreases as the signal becomes more informative. Finally, the pricing formulas indicate-not surprisingly — that if the signal in the limit fully resolves all uncertainty (i.e., $I \rightarrow 1$ ), the pricing function converges to the efficient price for all signal realizations; i.e., $p(\varepsilon) \rightarrow p^{*}(\varepsilon) \forall \varepsilon$. The mispricing becomes less severe, the more information is provided by the signal.

Somewhat counter-intuitively, our analysis suggests that the price system may be significantly distorted if market participants receive news that contains little information about asset fundamentals. Almost irrelevant news can lead to sudden declines in asset prices and to large deviations of the market price from its fundamental value. In the rational expectations literature, signals without any information content about economic fundamentals are called "sunspots." The way cognitive dissonance is modeled in this paper 
thus suggests one mechanism how beliefs in the influence of sunspots on asset prices can emerge.

\section{CONCLUDing Remarks}

This paper attempts to model financial markets where quasirational investor behavior based on cognitive dissonance emerges endogenously. In our model, investors have rational expectations ex ante, but-consistent with psychological research on cognitive dissonanceonce they have made their investment decisions, their utility-maximizing beliefs may change and they might be prompted to discard unfavorable information. We demonstrate how asset prices can overreact to news under some circumstances and underreact to new information under other circumstances. Viewed from a rational standpoint, the individual portfolio decisions are efficient only for signals in the neighborhood of ex ante expectations (in the interval $\left[\varepsilon_{1}, \varepsilon_{0}\right]$, see Figure 2). For all other realizations of the signal, the portfolio decisions of some or all agents are suboptimal and are based on only part of the available information. The more extreme (the more negative or the more positive) the information that is ignored, the more distorted asset prices become. If the extent of mispricing becomes large enough, informed investors who behave rationally can exploit the distorted price structure and make arbitrage profits that compensates them for the "cost" of experiencing cognitive dissonance. Given highly unfavorable information, informed investors who act rationally sell overpriced assets to investors who do not act rationally. Conversely, at slightly unfavorable signals and for highly favorable signals, informed investors buy underpriced assets from the investors who ignore information.

Since our approach is nonstandard, a few comments about modeling conflicting cognitions may be in order. In may cases, cognitive dissonance is interpreted as caused by perceived errors in past decisions. According to that interpretation, inconsistent cognitions reflect the trade-off involved in deciding whether or not to reshape one's portfolios in the second period. In light of this view, our model of homogeneous agents might appear to be an environment that does not lend itself to modeling cognitive dissonance, since investors' portfolios are identical in equilibrium (with pure strategies) regardless of whether they act rationally or quasirationally. While that is the general equilibrium outcome, from an individual's perspective, the situation looks different. Given unfavorable information, at the efficient price each investor would want to invest less in the risky asset-irrespective of the fact that in general equilibrium they collectively cannot do so. So even though in equilibrium investors hold the same portfolios, inconsistent cognitions can arise from the perception that, confronted with unfavorable information, in hindsight their original portfolio choice was in error. Our approach, in fact, is consistent with the view of the cognitive dissonance hypothesis that resolving conflicting cognitions does not require that previous decisions are revised-instead beliefs can be changed to resolve the conflict.

Applying cognitive dissonance-one of the most influential concepts in social psychology — to asset pricing has the potential for generating new insights into the functioning of financial markets. As our model demonstrates, investors' endogenous beliefs can lead to persistent over- and undervaluation of stocks. Further research along these lines 
may shed light on some financial "anomalies" such as the equity premium puzzle; that is, the fact that, over long time horizons, the return on equity appears to be too large relative to the return on safe government securities. Endogenous shifts from rational to quasirational behavior could generate asset price volatility that is closer to the large volatility actually observed. In a similar vein, shifts in behavior could provide a theory of stock market crashes - a goal that has eluded traditional theory. According to our view, the mechanism would, loosely speaking, be as follows: once a critical mass of adverse information (which initially is being ignored by investors) has accumulated, investors may suddenly realize their folly and then make more accurate assessments. This shift in behavior could trigger a sudden large drop in stock prices. Further research could also investigate the implications of quasirational investor behavior for effective regulation of financial markets, appropriate market microstructures, and financial disclosure requirements. As a first step in these directions, our environment could be generalized to a model with multiple risky assets to analyze possible spillovers across asset markets stemming from mispricing induced by cognitive dissonance. 
Figure 1. Value Functions of the Investors’ Optimization Problem

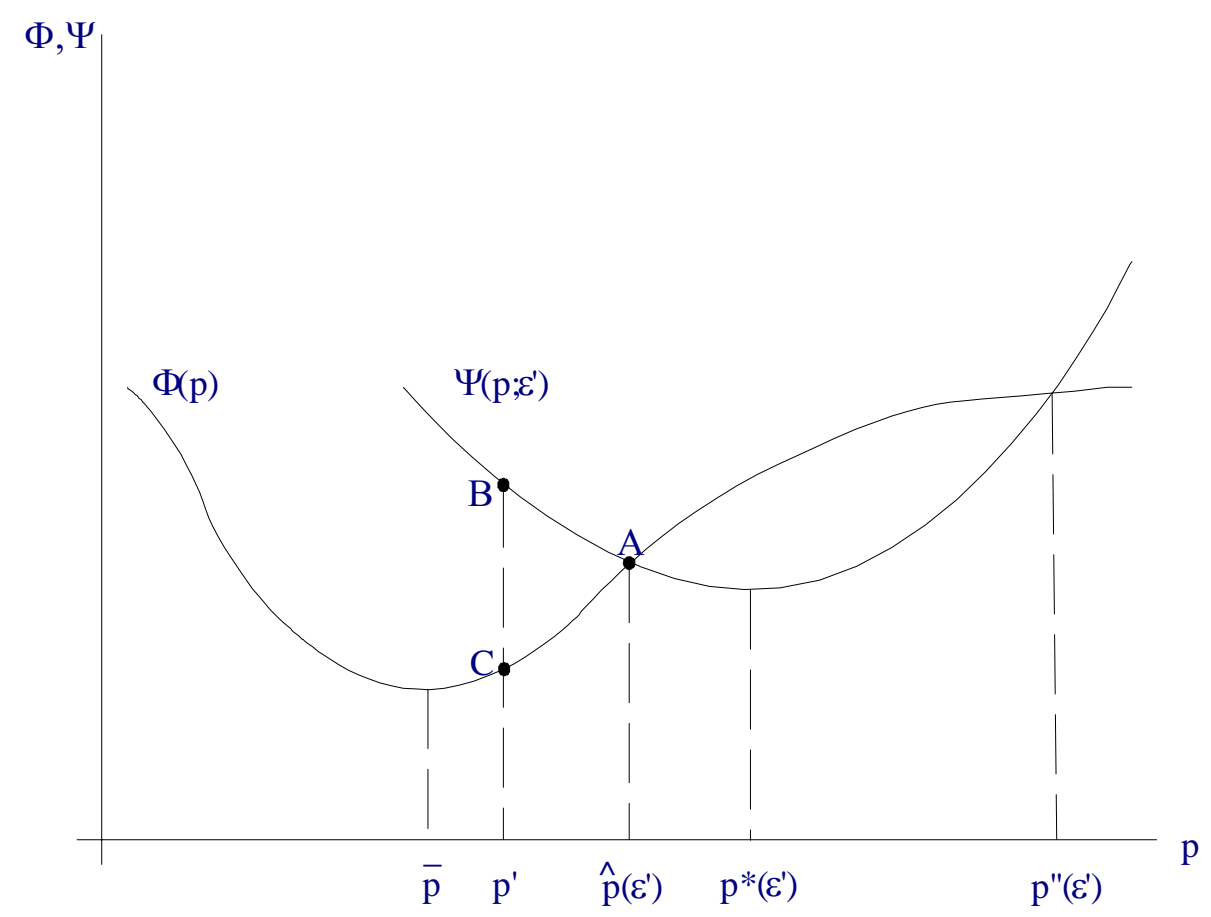


Figure 2. The Equilibrium Pricing Function

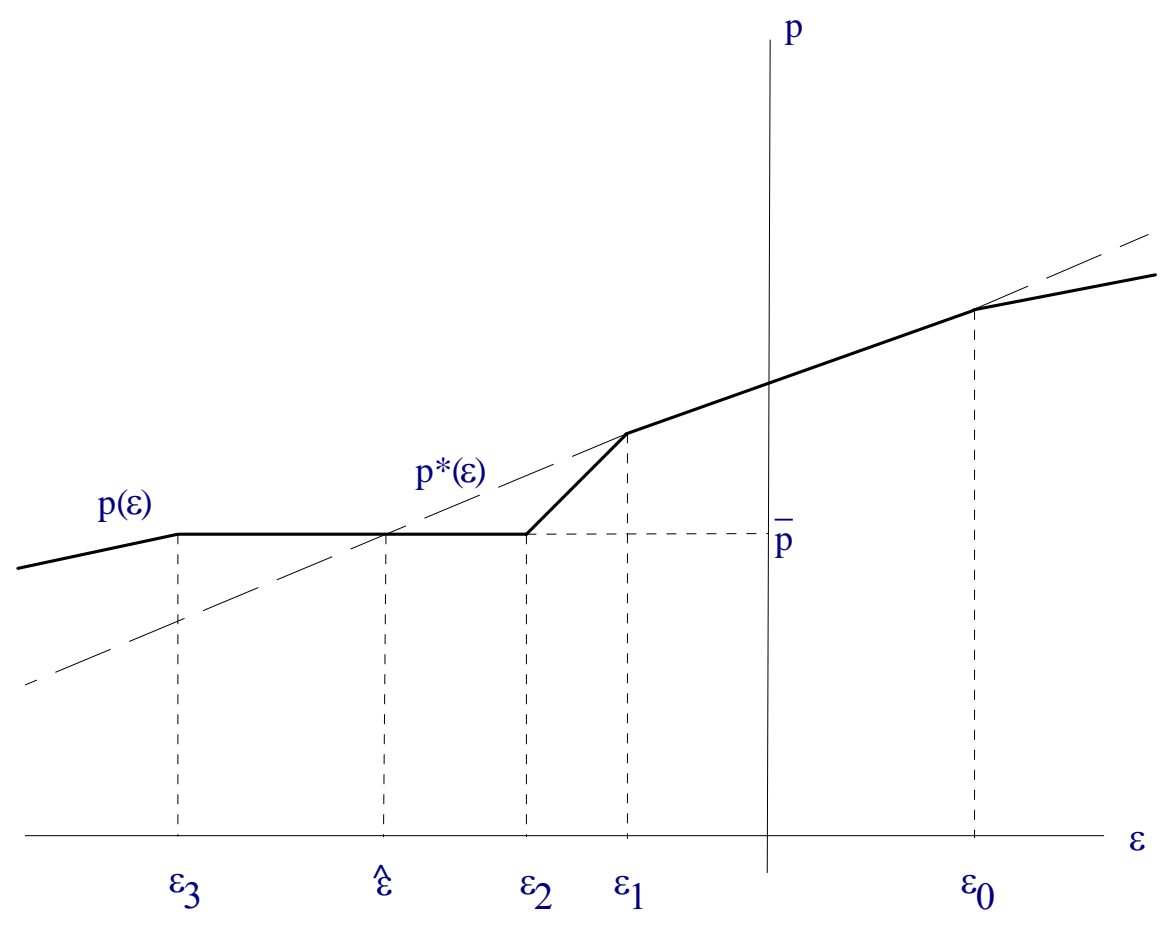




\section{References}

Aiyagari, S. Rao, and Mark Gertler, 1999, "Overreaction of Asset Prices in General Equilibrium,” Review of Economic Dynamics, Vol. 2, pp. 3-35.

Akerlof, George A., and W.T. Dickens, 1982, “The Economic Consequences of Cognitive Dissonance,” American Economic Review, Vol. 72, pp. 307-19.

Bansal, Ravi, and Amir Yaron, 2004, "Risks for the Long Run: A Potential Resolution of Asset Pricing Puzzles,” Journal of Finance, Vol. 59, pp. 1481-1509.

Barberis, Nicholas, and Richard Thaler, 2002, “A Survey of Behavioral Finance,” NBER Working Paper No. 9222 (Cambridge, Massachusetts: National Bureau for Economic Research).

Barberis, Nicholas, Andrei Shleifer, and Robert Vishny, 1998, “A Model of Investor Sentiment,” Journal of Financial Economics, Vol. 49, pp. 307-343.

Bernatzi, Shlomo, and Richard H. Thaler, 1995, "Myopic Loss Aversion and the Equity Premium Puzzle,” Quarterly Journal of Economics, Vol. 110, pp. 73-92.

Bakshi, Gurdip S., and Zhiwu Chen, 1996, “The Spirit of Capitalism and Stock Market Prices,” American Economic Review, Vol. 86, pp. 133-57.

Bernard, Victor L., 1992, “Stock Price Reactions to Earnings Announcements," in Advances in Behavioral Finance, ed. by Richard Thaler (New York; Russel Sage Foundation), pp. 303-40.

Brunnermeier, Markus, K., and Jonathan A. Parker, 2004, “Optimal Expectations,” NBER Working Paper No. 10707 (Cambridge, Massachusetts: National Bureau for Economic Research).

Campbell, John Y., and John H. Cochrane, 1999, "By Force of Habit: A Consumption-Based Explanation of Aggregate Stock Market Behavior,” Journal of Political Economy, Vol. 107, pp. 205-51.

Campbell, John Y., and Robert J. Shiller, 1988, “Stock Prices, Earnings, and Expected Dividends,” Journal of Finance, Vol. 43, pp. 661-76.

Carrillo, Juan D., and Thomas Mariotti, 2000, "Strategic Ignorance As a Self-Disciplining Device,” Review of Economic Studies, Vol. 67, pp. 529-44.

Chopra, Navin, Josef Lakonishok, and Jay R. Ritter, 1992, “Measuring Abnormal Performance: Do Stocks Overreact?” Journal of Financial Economics, Vol. 31, pp. 235-68. 
Cohen, Randolph B., Paul A. Gompers, and Tuomo Vuolteenaho, 2002, "Who Underreacts To Cash-Flow News? Evidence From Trading Between Individuals and Institutions,” Journal of Financial Economics, Vol. 66, pp. 409-62.

Cutler, David M., James M. Poterba, and Lawrence H. Summers, 1991, “Speculative Dynamics,” Review of Economic Studies, Vol. 58, pp. 529-46.

Daniel, Kent, David Hirshleifer, and Avanidhar Subrahmanyam, 1998, "Investor Psychology and Securities Market Under- and Overreaction,” Journal of Finance, Vol. 53, No. 6, 1839-1885.

Daniel, Kent, David Hirshleifer, and Siew Hong Teoh, 2002, “Investor Psychology in Capital Markets: Evidence and Policy Implications,” Journal of Monetary Economics, Vol. 49, No. 1, 139-209.

DeBondt, Werner F.M., and Richard H. Thaler, 1985, “Does the Stock Market Overreact?” Journal of Finance, Vol. 40, pp. 793-808.

_ Perspective,” in Handbook in Operations Research and Management Science, Vol. 9, Finance, ed. by Robert Jarrow and others (Amsterdam: Elsevier).

Fama, Eugene F., 1991, “Efficient Capital Markets: II,” Journal of Finance, Vol. 46, pp. 1575-1617.

— Journal of Financial Economics, Vol. 49, pp. 283-306.

Fama, Eugene F., and Kenneth R. French, 1988, "Permanent and Temporary Components of Stock Prices,” Journal of Political Economy, Vol. 96, pp. 246-273.

Festinger, Leon, 1957, A Theory of Cognitive Dissonance (Stanford, CA: Stanford University Press).

Fiske, Susan T., and Shelley E. Taylor, 1991, Social Cognition (New York: McGraw-Hill).

Gigerenzer, Gerd, and Reinhard Selten, 2001, Bounded Rationality: The Adaptive Toolbox (Cambridge, Massachusetts: MIT Press).

Grinblatt, Mark, Sheridan Titman, and Russ Wermers, 1995, "Momentum Investment Strategies, Portfolio Performance, and Herding: A Study of Mutual Fund Behavior,” American Economic Review, Vol. 85, pp. 1088-1105.

Grossman, Sanford J., and Joseph Stiglitz, 1980, “On the Impossibility of Informationally Efficient Markets,” American Economic Review, Vol. 70, pp. 393-408. 
Harmon-Jones, Eddie, and Judson Mills, 1999, “An Introduction to Cognitive Dissonance Theory and an Overview of Current Perspectives on the Theory,” in: Cognitive Dissonance: Progress on a Pivotal Theory in Social Psychology, ed. by E. HarmonJones and J. Mills (Washington, D.C.: American Psychological Association).

Hess, Patrick J., and Marc R. Reinganum, 1979, “Efficient Capital Markets,” Handbook of Financial Economics (Amsterdam: North-Holland).

Hirshleifer, David, 2001, “Investor Psychology and Asset Pricing,” Journal of Finance, Vol. 56, No. 4, 1533-97.

Hong, Harrison, and Jeremy C. Stein, 1999, “A Unified Theory of Underreaction, Momentum Trading, and Overreaction in Asset Markets,” Journal of Finance, Vol. 54, pp. 2143-84.

Jegadeesh, Narasimhan, and Sheridan Titman, 1993, "Returns to Buying Winners and Selling Losers: Implications for Stock Market Efficiency,” Journal of Finance, Vol. 48, pp. 65-91.

LeRoy, Stephen F., 1989, “Efficient Capital Markets and Martingales,” Journal of Economic Literature, Vol. 27, pp. 1583-1621.

Malkiel, Burton G., 2003, “The Efficient Markets Hypothesis and Its Critics,” Journal of Economic Perspectives, Vol. 17, pp. 59-82.

Mehra R., and Edward C. Prescott, 1985, “The Equity Premium: A Puzzle,” Journal of Monetary Economics, Vol. 15, pp. 145-61.

Odean, Terrance, 1998, "Volume, Volatility, Price, and Profit When All Traders Are Above Average,” Journal of Finance, Vol. 53, No. 6, 1887-1934.

Rabin, Matthew, 1998, “Psychology and Economics,” Journal of Economic Literature, Vol. 36, pp. 11-46.

Rabin, Matthew, and Joel L. Schrag, 1999, "First Impressions Matter: A Model of Confirmatory Bias,” Quarterly Journal of Economics, Vol. 114, pp. 37-82.

Rouwenhorst, K. Geert, 1998, “International Momentum Strategies,” Journal of Finance, Vol. 53, pp. 267-84.

Shiller, Robert J., 1981, “Do Stock Prices Move Too Much to be Justified by Subsequent Changes in Dividends?” American Economic Review, Vol. 71, pp. 421-36. , 1998, "Human Behavior and the Efficiency of the Financial System,” NBER Working Paper 6375 (Cambridge, Massachusetts: National Bureau for Economic Research). 
, 2003. "From Efficient Markets Theory to Behavioral Finance,” Journal of Economic Perspectives, Vol. 17, pp. 83-104.

Tversky, Amos, and Daniel Kahneman, 1974, “Judgment Under Uncertainty: Heuristics and Biases,” Science, Vol. 185, pp. 1124-1131.

West, Kenneth D., 1988, “Bubbles, Fads and Stock Price Volatility Tests: A Partial Evaluation,” Journal of Finance, Vol. 43, pp. 639-60.

Yariv, Leeat, 2002, “I’ll See It When I Believe It-A Simple Model of Cognitive Consistency,” mimeo, UCLA.

Zou, Heng-fu, 1994, “ ‘Spirit of Capitalism’ and Long-Run Growth,” European Journal of Political Economy, Vol. 10, pp. 279-93. 